\title{
Preparing for the Behavioral Health Impact of COVID-19 in Michigan
}

\author{
Evonne Edwards ${ }^{1,2} \cdot$ Carol A. Janney ${ }^{1,2,3} \cdot$ Amy Mancuso $^{1} \cdot$ Heide Rollings ${ }^{1,2} \cdot$ Amy VanDenToorn $^{1}$. \\ Mariah DeYoung ${ }^{1} \cdot$ Scott Halstead ${ }^{1} \cdot$ Mark Eastburg $^{1}$
}

Accepted: 26 October 2020 / Published online: 8 December 2020

(C) Springer Science+Business Media, LLC, part of Springer Nature 2020

\begin{abstract}
Purpose of Review As a global pandemic, COVID-19 has profoundly disrupted the lives of individuals, families, communities, and nations. This report summarizes the expected impact of COVID-19 on behavioral health, as well as strategies to address mental health needs during the COVID-19 pandemic and its aftermath. The state of Michigan in the USA is used to illustrate the complexity of the mental health issues and the critical gaps in the behavioral health infrastructure as they pertain to COVID-19. Scoping review was conducted to identify potential mental health needs and issues during the COVID-19 pandemic and its aftermath.

Recent Findings The ramifications of COVID-19 on mental health are extensive, with the potential to negatively impact diverse populations including healthcare providers, children and adolescents, older adults, the LGBTQ community, and individuals with pre-existing mental illness. Suicide rates, alone, are expected to rise for Michiganders due to the economic downturn, isolation and quarantine, increased substance use, insomnia, and increased access to guns associated with the COVID-19 pandemic.

Summary This report promotes awareness of a behavioral health crisis due to COVID-19. Increasing access to behavioral health care should minimize COVID-19's negative influence on mental health in Michigan. We propose a three-prong approach to access: awareness, affordability, and technology. Addressing workforce development and fixing gaps in critical behavioral health infrastructure will also be essential. These actions need to be implemented immediately to prepare for the expected "surge" of behavioral health needs in the ensuing months.
\end{abstract}

Keywords COVID-19 $\cdot$ SARS $\cdot$ Mental health $\cdot$ Substance use $\cdot$ Suicide $\cdot$ Telehealth

\section{Introduction}

As a global pandemic, COVID-19 has profoundly disrupted the lives of individuals, families, communities, and nations, infecting millions and killing more than a half

This article is part of the Topical collection on Complex MedicalPsychiatric Issues

The editors would like to thank Dr. Kamalika Roy for taking the time to review this manuscript.

Evonne Edwards

evonne.edwards@pinerest.org

1 Pine Rest Christian Mental Health Services, 300 68th St SE, Grand Rapids, MI 49548, USA

2 Division of Psychiatry and Behavioral Medicine, College of Human Medicine, Michigan State University, Grand Rapids, MI, USA

3 Department of Epidemiology and Biostatistics, College of Human Medicine, Michigan State University, East Lansing, MI, USA million people. While the physical health impacts of COVID-19 are salient in this pandemic, the less conspicuous impact of the pandemic and infection control strategies on behavioral health can be severe as well. This report summarizes the expected impact of COVID-19 on behavioral health as well as strategies to address mental health needs during the COVID pandemic and its aftermath [1]. The state of Michigan, USA, is used to illustrate the complexity of the mental health issues and the critical gaps in the behavioral health infrastructure as it pertains to COVID-19. It is evident, as outlined in this report, that "Michigan will experience a mental health crisis as a result of the aftershocks of COVID-19 unless we act now [1]."

Briefly, more than 84,000 Michigan residents have tested positive for COVID-19 and 6,219 have died prematurely due to this virus so far [2]. Many individuals infected with COVID-19 have died while quarantined from significant others, leaving behind family and friends who grieve alone [1]. Preparing for and treating this immense number of 
COVID-19 patients has overwhelmed healthcare systems, which are simultaneously facing financial distress as elective procedures are canceled, primary care offices are shuttered, and visits for non-COVID-related issues are minimized or postponed [1]. As a result, healthcare workers have been called upon to work long hours and, at times, provide care to COVID-19 patients with inadequate personal protective equipment, risking their own lives and accidental viral transmission to their families [1].

The Michigan "Stay Home, Stay Safe" executive order has effectively diminished the spread of COVID-19, but it has increased social isolation and weakened residents' access to their support systems, such as friends, extended family, coworkers, teachers, and religious communities [1]. Michigan's executive order and residents' own efforts to avoid infection have created large economic consequences, closing businesses (some temporarily but others permanently), spiking unemployment rates, and creating widespread financial stress [1].

\section{Methods}

A scoping review [3] was conducted due to the limited number of COVID-19 publications that identified potential mental health needs and issues during the COVID-19 pandemic and its aftermath. First, PubMed was searched using the keywords COVID-19, coronavirus, SARS, pandemic, and epidemic cross referenced with mental health, psychiatry, depression, anxiety, substance use, isolation, domestic violence, and suicide. Next, Michigan was added as a keyword to these initial searches. Over 102 articles were reviewed. Citations from pertinent articles were reviewed, as well as those articles that cited the pertinent articles that are bulleted in the reference list. Emphasis was placed on publications related to the 2003 SARS coronavirus as a means to project potential impacts of COVID-19 on mental health in Michigan. Timely information from internet searches of reputable medical institutions (National Institutes of Mental Health, CDC, Michigan Department of Health and Human Services, etc.) was also included.

Prior to publication, the original, unpublished report titled Preparing Michigan for the Behavioral Health Impact of COVID-19 [1] was posted on the Pine Rest Christian Mental Health Services' website on April 6, 2020, as a tool to educate legislators, professionals, and the public of the potential impacts of COVID-19 on mental health in Michigan. The original report was written and posted immediately with the aim of mitigating and minimizing the negative effects of the COVID19 pandemic on the behavioral health of Michigan residents. This scoping review highlights and updates the original report with the original authors' permission. The original, unpublished report is extensively cited to appropriately acknowledge their contributions to this scoping review.

\section{Potential COVID-19 Impacts on Mental Health in Michigan}

As summarized in Table 1 [1], the ramifications of COVID-19 on mental health are extensive and have the potential to impact large proportions of the Michigan population. An April survey of 24,155 Michigan residents found $79 \%$ of respondents reported concern about stress, loneliness, anxiety, and/or depression, with $29 \%$ indicating that they were "very" or "extremely" concerned about these mental health symptoms [70]. These concerns may be well-founded, as $32 \%$ of Michigan adults endorsed symptoms of an anxiety or depressive disorder in a June 2020 study [71]. Though widespread, these mental health impacts may be particularly negative for specific groups and likely deadly for many due to exacerbations of suicide risk factors.

\section{Risk Factors for Suicide in Michigan}

Notably, many of the factors impacted by COVID-19 and listed in Table 1 are well-established risk factors for suicide [1]. As succinctly stated by David Jobes, "We do not want a double tragedy. There are tragedies of people dying by this virus, every day. Our suicidal patients do not have to die as well [31]."

\section{Economic Distress}

Since the onset of the COVID-19 pandemic, the official USA unemployment rate has increased $11.2 \%$ to a striking $14.7 \%$ [20]. The true proportion of Americans currently out of work is likely even higher, as social isolation and stay-home orders have precluded many from actively seeking new jobs, a requirement to be included in the official unemployment rate [20]. Consistent with the national trend, unemployment insurance claims indicate that Michigan unemployment rate has risen dramatically from $3.6 \%$ in February 2020 to $21.7 \%$ by the end of April 2020 and is the 3rd highest state insured unemployment rate in the USA [21]. These unemployment rates are concerning in themselves but alarming in the context of mental health, due to the relationship between suicide and financial problems or unemployment. In a year without a substantial economic downturn, the Centers for Disease Control and Prevention (CDC) reported job loss or financial problems contributed to $16 \%$ of suicide deaths [28]. Suicide rates in prior economic recessions increased $1.3 \%$ for every $1 \%$ rise in the unemployment rate $[1,22]$. Given this relationship, we estimate an approximately $15 \%$ increase in the national suicide rate and a $24 \%$ increase in the Michigan suicide rate during the coming year based on the unemployment rate 


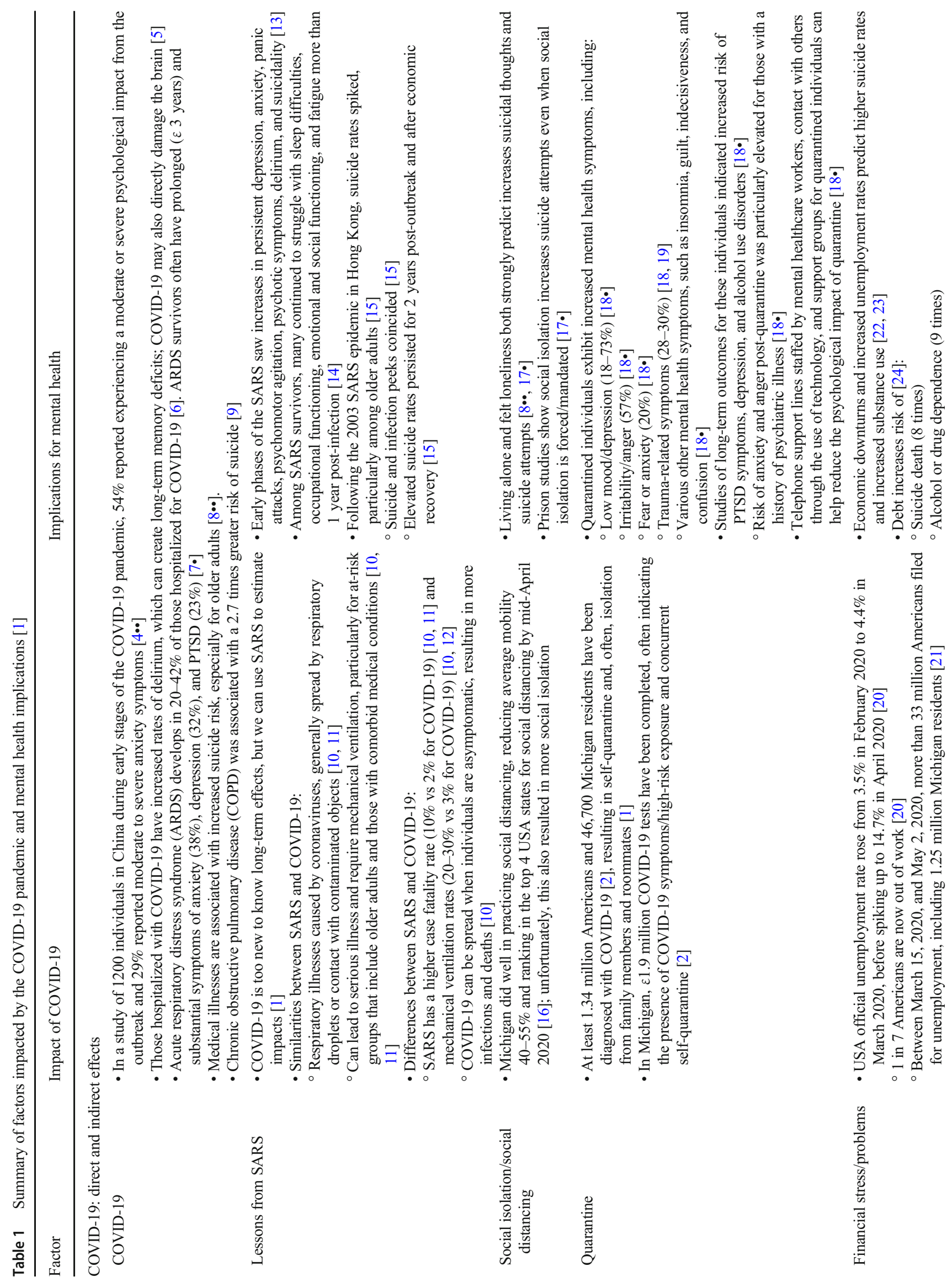




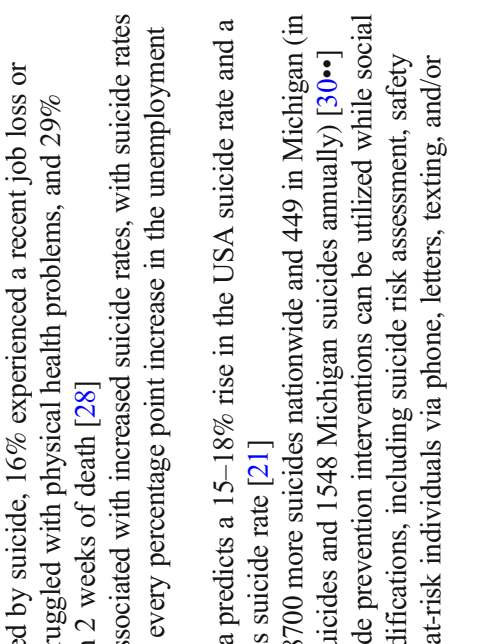

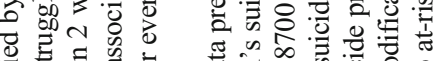

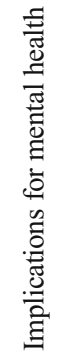

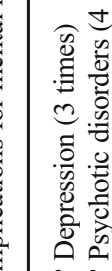

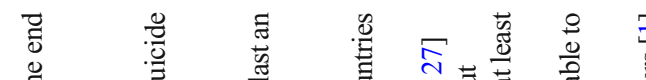

वृ.

胥

花

要

苞趝

苞

총.

害.

悹

总

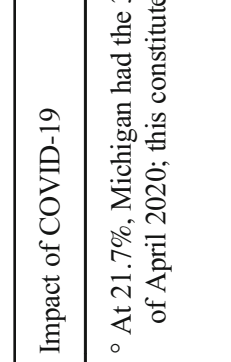

을

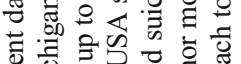

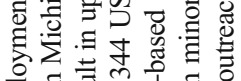

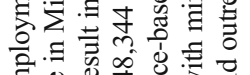

约

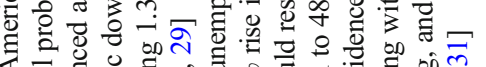

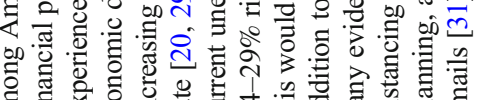

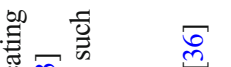

हैं

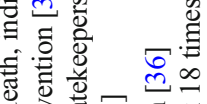

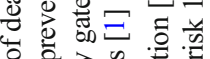

語总言总

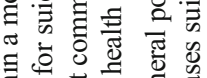

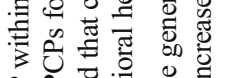

Uิ

:

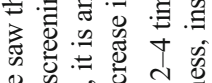

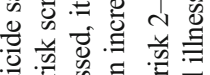

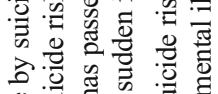

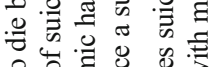

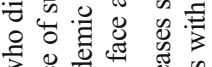

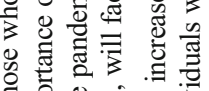

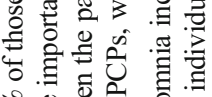

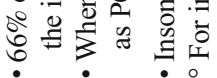

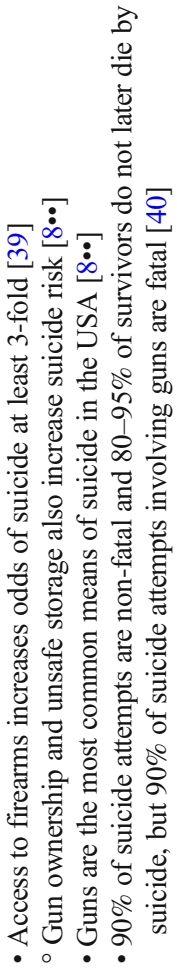

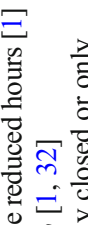

这

늘

卷 छ

즌 는

氞券

흥 氙

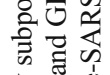

言起

运

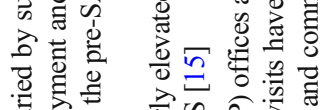

흥 든

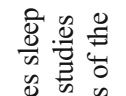

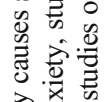

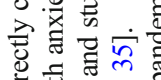

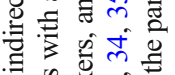

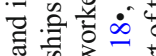

要

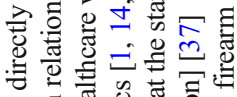

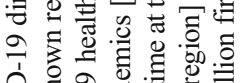

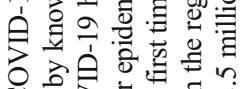

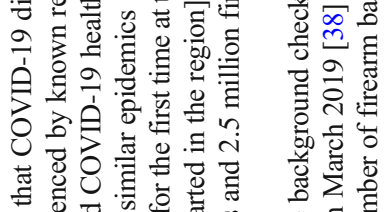

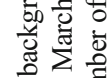

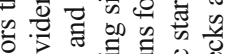

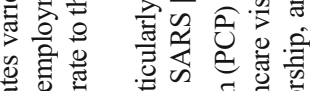

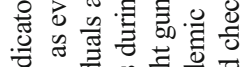

总要言

焉焉

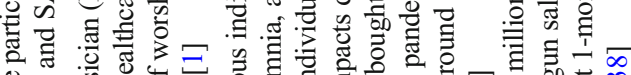

을

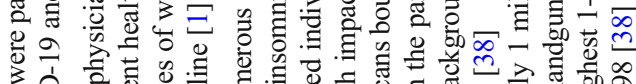

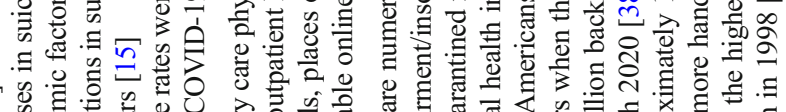

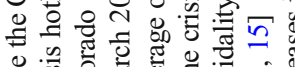

दे

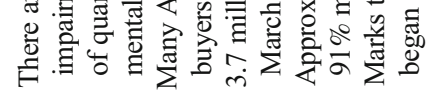

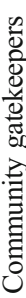

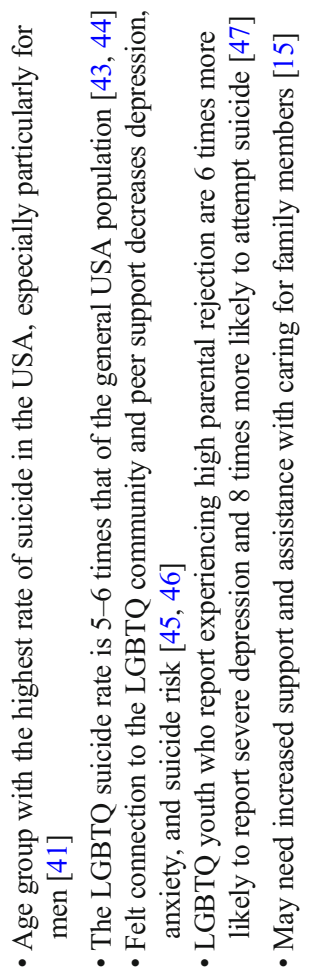

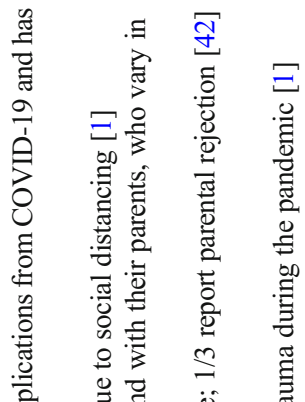

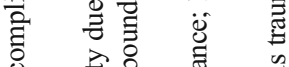

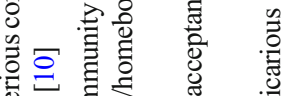

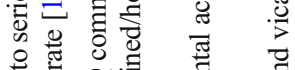

율

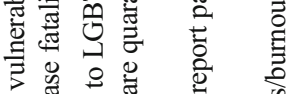

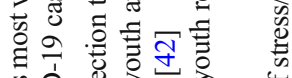

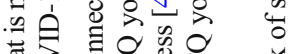

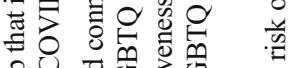

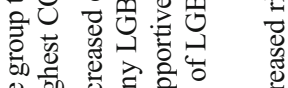

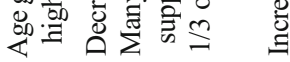




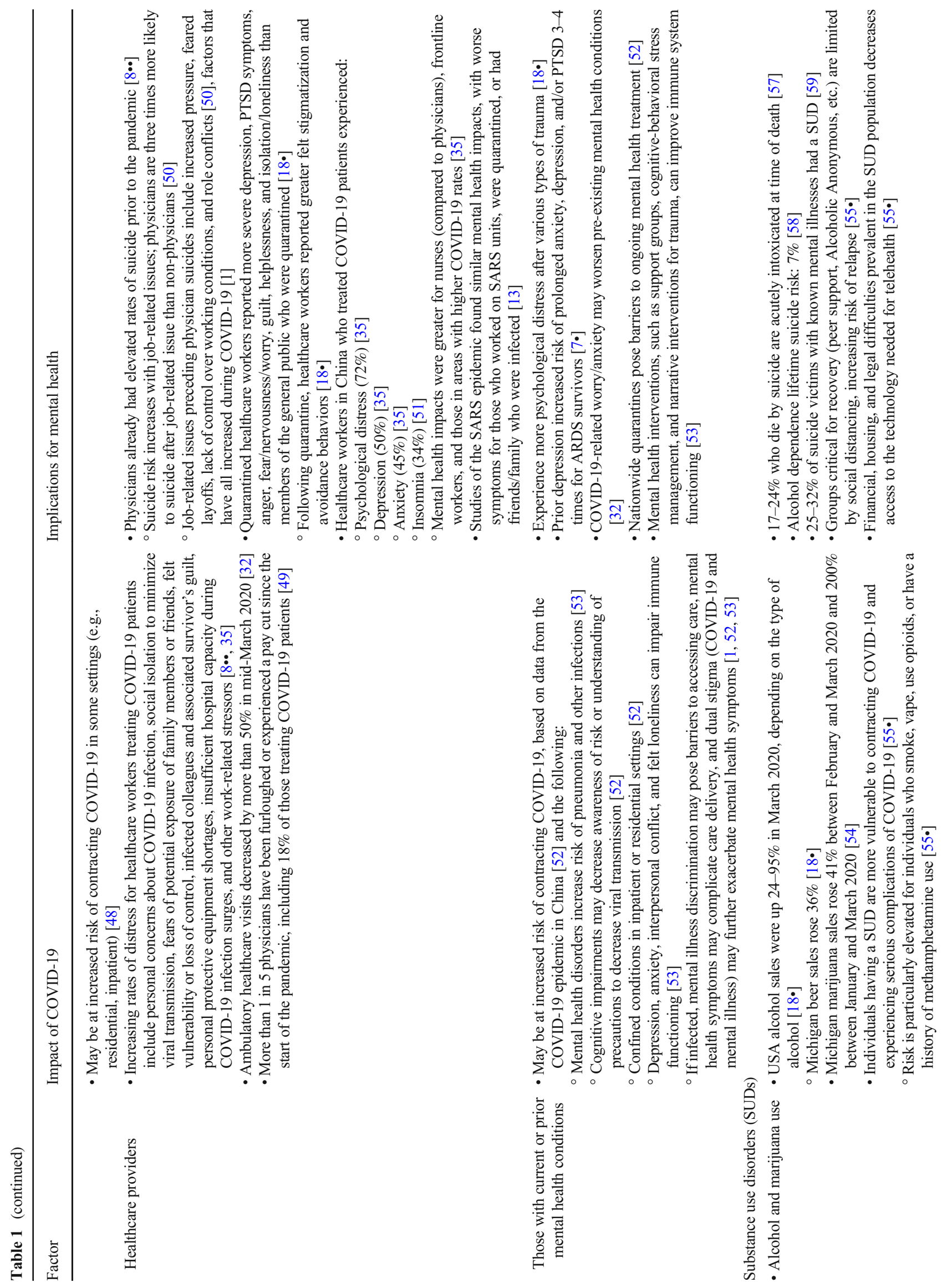



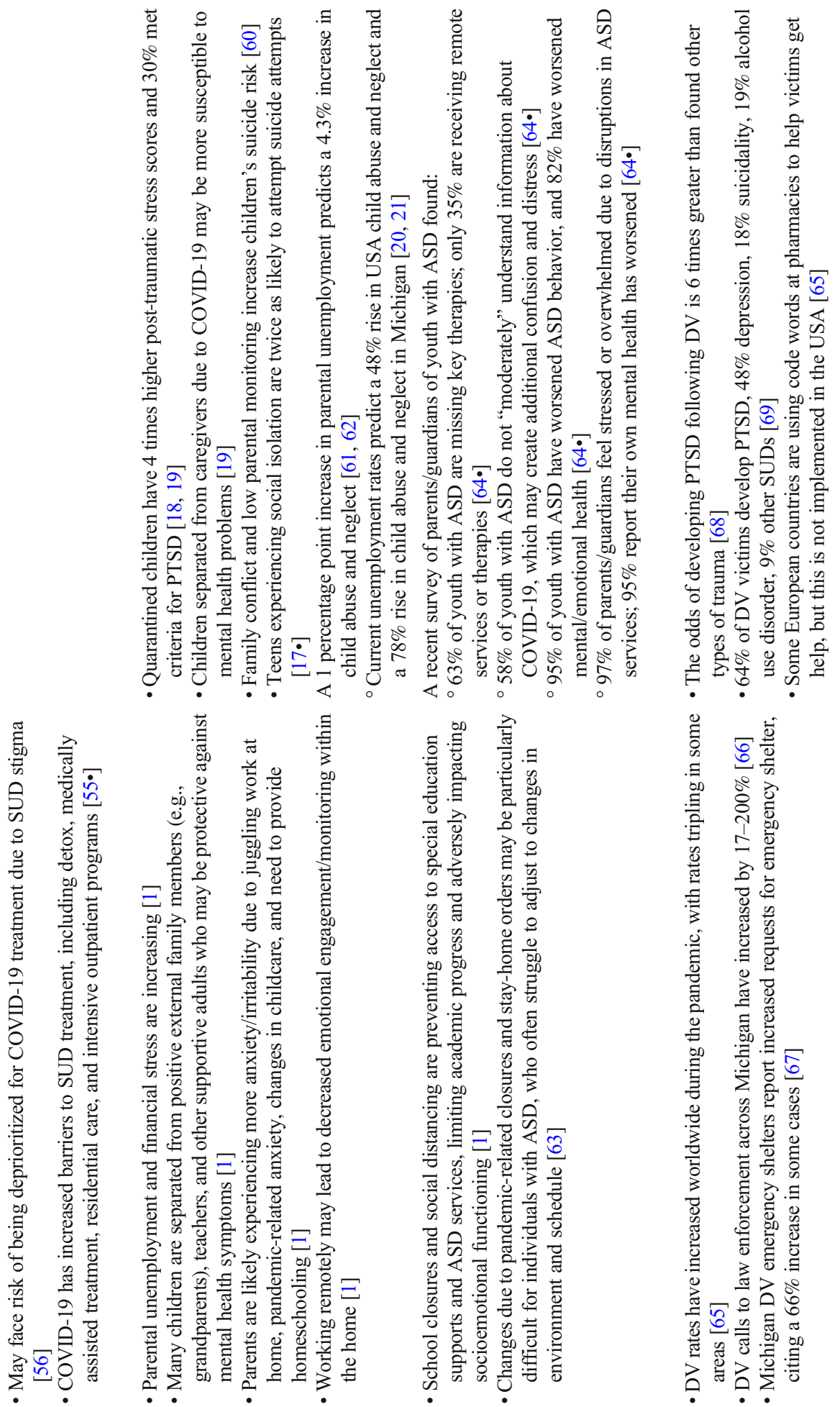

苛

잉 웡

:

霰

密

ड

चี

茎

辛

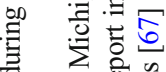

of 0

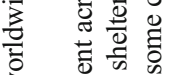

3 일.

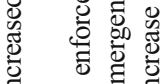

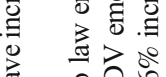

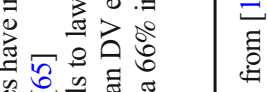

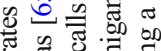

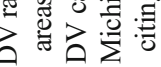
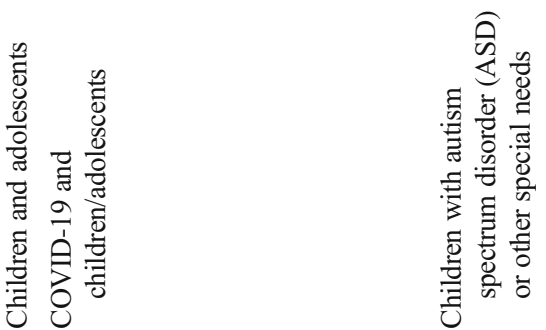

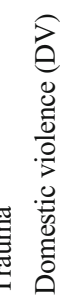

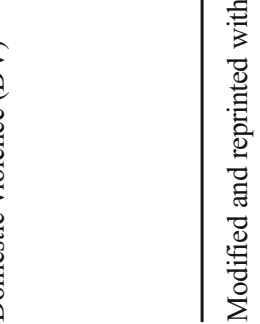


alone. Nationally, suicide hotlines have recently reported 47 to $300 \%$ increases in crisis calls [25, 26]. Within Michigan, the mental health impact of the economic decline was felt by early April, with approximately a third of Michiganders indicating they were "very" or "extremely" concerned about financial security [70].

\section{Isolation/Quarantine}

Social distancing in Michigan was mandated by the 'Stay Home, Stay Safe' executive order from March 22 to May 31, 2020. Although social distancing will likely save lives by decreasing the spread of COVID-19, for many individuals, it will increase social isolation and felt loneliness, known risk factors for suicidal thoughts and suicide attempts $[8 \bullet \bullet, 17 \bullet]$. In addition, social distancing limits involvement in religious communities and services, reducing the protective effects these practices typically have on suicide risk, such as a five times lower risk of suicide for individuals who attend religious services weekly compared to those who do not $[1$, $8 \bullet \bullet$. Identified protective effects of religious service attendance on suicide attempts and deaths remain after controlling for social interaction and support, suggesting this effect may endure the pandemic-related reduction in religious social support [72]. Unfortunately, the protective effect of religious service attendance on suicidal ideation does appear to be mediated by social support, and other protective aspects of religion and spirituality, such as purpose or meaning in life, may be negatively impacted by lack of formal religious participation $[56,73]$.

The social impact of COVID-19 is often greater for those who contract the disease, including more than 84,000 Michigan residents who had a COVID-19 diagnosis as of August 4, 2020 [2]. Once diagnosed with COVID-19, individuals are often quarantined, which extends social isolation to separation from family members and roommates [1]. Prior studies have shown increases in depression, acute stress disorder, post-traumatic stress disorder (PTSD), anxiety, insomnia, and cognitive impairments with quarantine [18•]. Individuals with pre-existing mental illness exhibited even greater risk of anxiety, depression, anger, and other mental health symptoms following quarantine [18•].

\section{Increased Substance Use}

The USA entered 2020 within a growing substance use disorder (SUD) crisis, and data suggests this crisis was further exacerbated by the COVID-19 pandemic [1]. In Michigan, alcohol sales have increased $41 \%$ and marijuana purchases have nearly doubled since the beginning of the pandemic $[54,74]$. The use of alcohol and other substances has also been shown to increase with unemployment during prior economic recessions [23]. Although results of large-scale SUD studies during the pandemic are not yet available, at least one Michigan healthcare system reported a $20-30 \%$ increase in new patients with SUDs by May 2020, suggesting a rising incidence of SUDs [75].

In addition to increased risk of SUD development, pandemic-related factors pose significant hazards for those with existing SUDs. Specifically, 58\% of patients diagnosed with an existing SUD increased their use during unemployment [55•]. The rise in alcohol and marijuana consumption also increases the likelihood that those in SUD recovery will observe others' increased use of substances, a known risk factor for relapse [55*]. The risk of substance use relapse is also greater with social isolation resulting from social distancing [55•].

At the same time, support groups critical for SUD recovery and relapse prevention are currently limited by social distancing and restrictions on gatherings [55•]. While many 12 -step groups have been able to transition to online platforms, they include barriers for new and current members, such as the need to use passwords to prevent "zoom-bombing" and the decreased felt connectedness some members report when attending online meetings rather than in-person meetings [6]. As self-help groups are attended by half of those who receive treatment for SUDs, these limitations impact a significant number of individuals seeking treatment or in recovery [76]. While some Alcoholics Anonymous Michigan districts clearly documented whether meetings will occur in-person and how to locate online meetings (e.g., District 3, Genesee County, District 11), others refer to social media or simply state that most groups are now on Zoom. Fortunately, at least 14 online support groups are available in West Michigan that focus on various populations, including alcoholics, adult children of alcoholics, family members of current, prior, or suspected substance users, narcotics, refugee, women, and LGBTQIA.

Those individuals who need a higher level of care may face further barriers to care. Many residential rehabilitation and medical detoxification facilities have limited admissions in order to facilitate social distancing, provide quarantine for new patients and those exhibiting COVID-19 symptoms, and adhere to guidelines from the American Society of Addiction Medicine (ASAM) and state-level executive orders [77, 78]. Within Michigan, various residential programs have reported reduced access, with Detroit-area residential treatment facilities reporting $30 \%$ reductions in capacity [79].

In addition to SUD risk, increased substance use can directly contribute to suicides [1]. It is estimated that $17-24 \%$ of individuals who die by suicide were acutely intoxicated at the time of death [57]. The lifetime suicide risk for individuals diagnosed with depression, bipolar disorders, and psychotic disorders is substantial, but is exceeded by the $7 \%$ lifetime suicide risk found for individuals diagnosed with alcohol 
dependence [58]. These coinciding risk factors with potentially lethal outcomes highlight the need to ensure SUD programs and well-trained staff are available to address the anticipated growth in substance use disorders in Michigan [1].

\section{Insomnia}

Sleep impairments and insomnia have been attributed to various aspects of the COVID-19 pandemic. Quarantined individuals, healthcare workers treating COVID-19, those with elevated anxiety, and survivors of COVID-19 may be at greater risk of insomnia than other individuals $[1,14,18 \bullet, 51]$. The resulting impact on suicide risk is substantial. Insomnia increases the risk of suicide two to four times within the general population and 18 times for individuals with mental illness [36].

\section{Access to Community Gatekeepers}

Primary care providers (PCPs) are important community gatekeepers for mental health issues, prescribing $79 \%$ of antidepressants and treating $60 \%$ of individuals receiving care for depression in the USA $[1,80]$. Due to efforts to slow the transmission of COVID-19, outpatient healthcare visits have dramatically decreased, including a $49 \%$ decrease in primary care visits and a $30 \%$ decrease in behavioral health visits [32]. This decline in medical care visits may reflect delayed helpseeking by patients or decreased access to treatment, resulting in worsening mental health symptoms [1].

The Joint Commission, a large USA hospital-accrediting organization, predicted four "waves" of morbidity and mortality in the pandemic: (1) a wave due directly to COVID-19, (2) a wave from urgent non-COVID-19 conditions due to limited resources and diminished help-seeking, (3) a wave from chronic conditions due to interruptions in care, and finally (4) a large wave due to the mental health impacts of the pandemics and similar interruptions in mental health care and diminished help-seeking as those expected in the second and third waves [81].

Typically, Michigan death rates tend to decline gradually from January to June (Fig. 1) [82]. In 2020, this pattern was disrupted and attributed to the COVID-19 pandemic. Excluding confirmed COVID-19 deaths, Michigan death rates increased in March (6\%) and peaked in April (16\%) compared to 2019 [82]. Excess Michigan deaths $(n=1995)$ occurred from non-COVID-19-related causes during March, April, and May of 2020 compared to the same months in 2019. Early in the pandemic (March), the majority of these excess deaths were attributed to causes that may reflect missed COVID-19 diagnoses or complications caused by the virus itself, including pneumonia and influenza (52\% increase), septicemia ( $42 \%$ increase), and COPD (11\% increase) [10, 82]. Later in the pandemic (April), excess deaths were attributed to pneumonia and influenza (24\%), heart disease (27\%), and strokes (20\%) and may correspond to the predicted second wave of urgent non-COVID-19 conditions [81, 82]. Fewer excess deaths due to COPD and sepsis were found in April than March, possibly due to substantial increases in COVID-19 testing (in April, Michigan's COVID-19 test positivity rates steadily declined from 41 to $10 \%)[2,82]$. This second wave of urgent, non-COVID-19 conditions (heart attacks and strokes) may reflect barriers to care or delayed helpseeking for urgent conditions during the pandemic, as reflected in a $50 \%$ decrease in emergency department visits at Michigan hospitals, a 17\% decrease in Michigan emergency medical services (EMS) transports between March 15 and May 23, 2020, and a 62\% increase in out-of-hospital deaths during this same timeframe [83, 84]. Consistent with mortality data, these changes were most pronounced for heart attacks (10\% decrease in EMS transports, $43 \%$ increase in out-of-

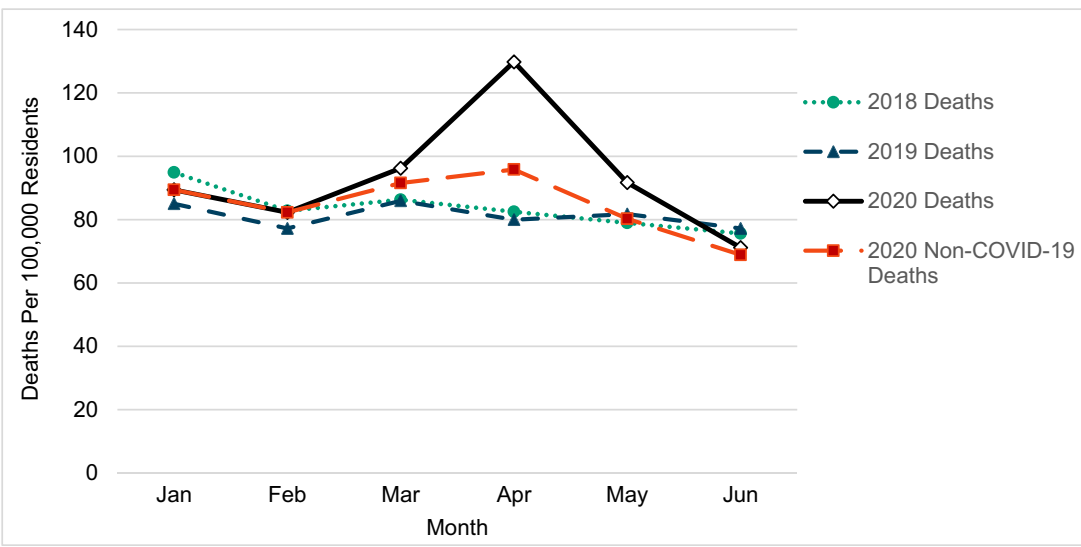

Fig. 1 Increase in Michigan 2020 all-cause mortality rates and nonCOVID-19 mortality rates compared to two prior years. Data from the Michigan Department of Health and Human Services (MDHHS) shows increases in both deaths per 100,000 residents from all causes of death (solid line with diamond markers) and deaths per 100,000 residents from
non-COVID-19 causes of death (long-dashed line with square markers) beginning in March, peaking in April, and returning to rates comparable to those seen in 2018 (dotted line with circle markers) and 2019 (shortdashed line with triangle markers) 
hospital cardiac arrests) and strokes (12\% decrease in stroke patient transports) in Michigan [84].

Due to pandemic-related barriers to care and delayed helpseeking, another wave of new patients experiencing distress and mental health symptoms is expected to inundate PCPs as non-COVID-19 medical visits resume [1]. It is essential that PCPs have a system in place to easily refer individuals to mental health services and specialists should this occur.

\section{Physical Health Problems}

Among COVID-19 confirmed cases in the USA, approximately $19 \%$ are hospitalized and $6 \%$ are admitted to the intensive care unit (ICU) [10]. Generally, patients who receive ICU medical care and recover have an increased risk for mental health issues [1]. The term post-ICU syndrome was coined to describe the high prevalence rates of post-traumatic stress symptoms (19-39\%), anxiety (23-62\%), and depression (17$43 \%$ ) that persist after physical recovery [34, 85]. These rates of mental illnesses are equivalent to rates observed in survivors of acute respiratory distress syndrome (ARDS), an acute lung condition that afflicts up to $42 \%$ of patients hospitalized for COVID-19 [10, 85].

Aside from pulmonary symptoms, patients hospitalized with COVID-19 may develop cardiac arrhythmia (17\%) and/or experience acute cardiac injuries (7-20\%) [86]. It is expected that the odds of suicide will be increased two to three times for survivors of severe cases of COVID-19 based on the odds ratios found for patients with other significant pulmonary and cardiac health conditions [9]. Based on similarities between COVID-19 and SARS coronavirus (SARS-CoV), survivors of severe cases of COVID-19 will likely experience ongoing physical health concerns similar to those experienced by the survivors of SARS, such as shortness of breath, chronic lung disease, kidney disease, fatigue, and/or insomnia [1, 14]. As with many chronic health conditions, these aftereffects are predicted to adversely impact survivors' mental health and suicide risk $[1,9 \bullet]$.

\section{Access to Guns}

USA gun sales escalated with the onset of the COVID-19 pandemic [1]. In March 2020, handgun sales increased 91\% and overall firearm purchases increased $85 \%$ compared to the prior year, with many purchases by first-time buyers [37, 38]. This rise in gun ownership predicts a subsequent increase in suicide deaths based on prior studies identifying a three-fold increase in the odds of suicide when firearms were available in the home [39]. This relationship between firearm access and suicide may be due to the substantially greater lethality of guns than most other methods of suicide attempts, resulting in guns being the most common method of suicide deaths in the USA $[8 \cdot \bullet, 40]$.

\section{Populations at Risk for Mental Health Issues}

Many of the risk factors identified thus far will impact many, if not most, Americans and Michigan residents. Due to the differential impact of COVID-19 and its associated risk factors on various populations, however, certain groups are at greater risk of mental illness, suicide, and substance use disorder than others [1]. As described below and summarized in Table 1, we expect mental health within the following populations to be significantly impacted by the COVID-19 pandemic: healthcare providers, older adults, children and adolescents, LGBTQ community members, individuals with preexisting mental illness, and individuals at risk of domestic violence [1].

\section{Healthcare Providers}

In addition to experiencing many of the stressors and risk factors described thus far, healthcare providers are experiencing additional stressors due to their professional roles [1]. Due to close contact with COVID-19 patients, in conjunction with inadequate personal protective equipment, healthcare providers are experiencing increased fears of personal infection and worries about accidental exposure of family members to the COVID-19 virus [8••, 35]. Paradoxically, the actual mechanism to prevent transmission to loved ones (social distancing and isolation) may weaken providers' emotional support systems and resilience [1]. The emotional impact of isolation may be particularly heightened for healthcare providers [1]. Studies examining the psychological impact of epidemic-related quarantines found that, in comparison to quarantined members of the general public, quarantined healthcare providers experienced more severe depression, PTSD symptoms, anger, guilt, helplessness, felt isolation or loneliness, and anxiety symptoms, such as fear, nervousness, and worry [18•].

Aside from these personal concerns, healthcare providers may also be experiencing professional stressors that range from inadequate supplies of personal protection equipment to the emotional strain of caring for distressed patients with COVID-19 [1]. These frontline workers may be experiencing fear, grief, survivors' guilt, and moral injury as they triage patients in life-and-death COVID-19 scenarios, assess best chances of patients' survival, and observe co-workers and friends become infected and sometimes die [1, 35]. Apart from direct impacts of COVID-19, initial reports found a $34 \%$ increase in insomnia, 50\% increase in depression, $45 \%$ increase in anxiety, and $72 \%$ increase in psychological distress among frontline COVID-19 healthcare workers in China $[35,51]$.

In addition to these direct mental health impacts of the pandemic on healthcare workers, the healthcare system has been faced with rising costs and plummeting revenue, resulting in the loss of 43,000 healthcare jobs by April 
2020 and an estimated $\$ 36.6$ billion net loss nationwide by the end of June 2020 [87, 88]. Throughout Michigan, health systems will experience a significant operational loss despite federal funds being allocated to health systems through the CARES Act. In total, Michigan health systems received 4.4 billion dollars from COVID-19 relief funds and Medicare advanced reimbursement loans [89]. Due to how fund allocation was calculated, Michigan received only $\$ 31,045$ per COVID-19 case, $\$ 130,000$ less than the national average of $\$ 160,286$ per case [89]. The University of Michigan Medicine initially budgeted $\$ 175$ million in profit prior to COVID-19 [90]. However, despite $\$ 136$ million in federal funds, and employee furloughs and attrition, Michigan Medicine now projects to lose \$3 million this year [90]. Other state health systems, such as Henry Ford and Ascension Health are expecting losses of $\$ 500$ million and $\$ 2$ billion accordingly [90].

These financial woes of the healthcare system directly impact the personal financial stress of healthcare workers, regardless of their income or position in the organization. In Michigan, we observed executives and administrators taking temporary pay cuts (5-70\%) and no bonuses [91]. Consistent with nationwide reports of nearly $20 \%$ of physicians reported being furloughed or experiencing a pay cut by April, Michigan physicians have experienced pay cuts and hour reductions $[49,92]$. Healthcare workers lower on the pay scale have experienced the greatest financial stress due to furloughs, terminations, reduced working hours, and greater risk of COVID-19 exposures.

A Michigan-based nonprofit research organization directly assessed these stressors in an April survey of 210 ambulatory healthcare clinics in Great Lake states, with $50 \%$ of respondents located within Michigan and $76 \%$ working in privately owned clinics [93]. A majority of respondents reported being "very" or "extremely" concerned about high levels of stress and anxiety (67\%) [93]. The percent of respondent expressing they were "very" or "extremely" concerned about COVID-19 infection of clinicians (72\%), staff (71\%) or family members (70\%) was surpassed only by revenue concerns $(84 \%)$, with $63 \%$ indicating they were "extremely" concerned about their ability to remain operational due to lost revenue [93]. Only $13 \%$ were confident in their personal protective equipment [93].

These additional mental health burdens for healthcare providers are occurring within a context of elevated suicide rates for physicians that predates the COVID-19 pandemic $[8,50]$. Because of job-related stressors, physicians are three times more likely to die from suicide than nonphysicians [50]. Unfortunately, the COVID-19 pandemic has generated numerous job-related stressors for physicians and other healthcare providers that may result in even higher rates of physician suicide unless preventive measures are quickly implemented [1].
As illustrated in the vignette below, mental health providers are experiencing elevated rates of stress, burnout, and vicarious trauma, which may compromise the state's ability to effectively respond to the projected behavioral health crisis associated with COVID-19 pandemic and its aftermath [48].

\section{On the Mental Health Frontlines: a Clinical Vignette [1] Provided by Evonne Edwards, PhD}

Exhaustion and vicarious trauma are already impacting some mental health providers during the early weeks of the COVID19 pandemic [1]. As explained by one Michigan therapist working with a patient infected with COVID-19, "You're in session with someone you have a relationship with, that you have worked with a couple years, that you may not see again [1]." During therapy, the clinician remains focused on the patient, supporting them as they process painful emotions and make the difficult decisions that accompany a lifethreatening disease. "Afterwards, you have your own grief and loss that you have to process and deal with, but when you're at home, with your family [due to teleworking], there is less space to process it," states one Michigan therapist [1]. "You cannot discuss it with your family and you do not have your colleagues right next door to consult and process with, so your own emotional processes can get pushed to the side and not dealt with. And then you have two or three sessions in a row like that [1]." It is the role of the clinician to help others manage anxiety; however, during this pandemic, clinicians may struggle to manage their own, a balance "that's easier some days than others [1]."

\section{Older Adults}

Older adults, over the age of 60 , are the most vulnerable to infection, serious complications, and fatality due to the COVID-19 virus $[1,10]$. In Michigan, 35\% of COVID-19 cases and $87 \%$ of COVID-19 deaths are individuals aged 60 or older [94]. Prior to the COVID-19 pandemic, older men already had the highest rate of suicide of any age and gender group, with men age 75 and older having the highest suicide rate in Michigan of any age and gender group [8・•, 30, 41]. The risk of suicide is even greater for older adults with medical illnesses $[8 \cdot \bullet, 9 \bullet, 41]$. This combination of general medical and mental health risk factors predicts a larger increase in suicide rates for older adults than the general population, a prediction consistent with analyses of Hong Kong suicide rates following the 2003 SARS epidemic [15].

Many daily activities for older adults residing in assisted living and long-term care facilities have been disrupted due to Michigan executive orders and infection control guidelines, including mandatory cancelation of communal dining and all external group activities and the prohibition of visitors apart from those in specific circumstances (e.g., to provide medical 
care or support activities of daily living, to exercise power of attorney, or visiting an individual in critical condition or hospice care) $[78,95]$. Though necessary to prevent rapid spread of COVID-19 infection and deaths in these vulnerable populations, these executive orders have resulted in increased social isolation, loneliness, and disrupted daily routines for many older adults.

Light exposure and daily routines are essential in maintaining an optimal circadian rhythm [96]. To prevent a compounding of risk by sleep difficulties resulting from disrupted circadian rhythms, it is important for nursing home facilities to prioritize daily light exposure and support older adults in developing new daily routines to minimize disruptions to circadian rhythms [97]. While older adults may be less familiar with virtual visits, staff in care facilities can help older adults, including those with cognitive impairments, utilize technology to connect with friends or family members.

\section{Children and Adolescents}

Children and adolescents are not spared from a multitude of COVID-19-related suicide risk factors [1]. Specifically, they may experience increased family conflict and witness family members struggling with increasing levels of stress, fear, and anxiety [1]. Lack of parental engagement and monitoring may result, as family members attempt to balance childcare, homeschooling, and work [1]. Family conflict and inadequate parental monitoring increase the odds of suicidal thoughts, non-suicidal self-injury, and suicide attempts for children [60]. Social distancing may result in isolation from positive external supports, limiting important protective factors that may otherwise mitigate suicide risk for these children and adolescents [1]. Prior research found teens experiencing social isolation have twice the suicide attempt risk, suggesting social distancing may be particularly deleterious for adolescents $[17 \bullet]$.

The risk of child and adolescent trauma may also be higher during the "Stay Home, Stay Safe" executive order [1]. Being isolated within the home environment, youth may witness increased anger and irritability that may erupt into fights, domestic violence, and/or child abuse [1]. Studies of child abuse and economic factors found risk of child abuse and neglect increased $4.3 \%$ with each $1 \%$ increase in parental unemployment [61, 62]. Based on current rates of unemployment in Michigan, child abuse and neglect can be expected to increase by $78 \%[1,21]$. Alarmingly, the odds of suicide are three to five times greater among victims of child abuse and neglect compared to non-victims [98].

The majority of children diagnosed with intellectual/ developmental disabilities or autism spectrum disorder (ASD) $(63 \%)$ have not received key therapies during the COVID-19 pandemic as a result of statewide school closures and the cancelation or postponement of non-life-saving medical treatments and procedures [64•]. Overwhelmingly, the impacted children exhibited worsened ASD behaviors $(95 \%)$ and mental and emotional health $(82 \%)$, as reported by parents and guardians [64•]. These parents/guardians also reported feeling overwhelmed or experiencing greater stress due to service disruptions for their child (97\%) [64•]. Not unexpectedly, these parents/guardians reported worsening of their own mental health [64•].

\section{LGBTQ Community}

The risk of suicide is five to six times greater in members compared to non-members of the LGBTQ community [43, 44]. Approximately, one-third of LGBTQ youth live with parents who do not support their LGBTQ child, and the risk of suicide attempts is eight times higher for these LGBTQ individuals than other LGBTQ youths [47]. Previous studies have shown that connectedness to LGBTQ communities and peer support can decrease depression, anxiety, and suicide risk for LGBTQ individuals, and even mitigate the damage from parental rejection or family victimization $[45 \bullet, 46]$. Hence, a further escalation of suicide risk is projected for the LGBTQ community, especially LGBTQ youth, due to social distancing measures that may isolate them with non-supportive family members and separate them from protective social supports during the COVID-19 crisis [1].

\section{Individuals With Pre-existing Mental IIIness}

Impaired immune functioning has been exhibited among individuals experiencing depression, anxiety, interpersonal conflict, and/or loneliness [53]. Given that individuals with mental health disorders have an elevated rate of contracting pneumonia and other respiratory infections and reports from China identified these individuals as particularly vulnerable to COVID-19 infection, individuals with pre-existing mental health issues may have a greater likelihood of contracting COVID-19 than other individuals $[1,52,53]$. Individuals in need of residential mental health are experiencing barriers to treatment due to the infection control-related reductions in census and admission, similar to those discussed for residential SUD treatment. Individuals currently receiving or in need of residential mental health or SUD treatment may experience barriers to treatment and additional mental health difficulties due to infection control policies. Vocational programs, crisis residential programs, and psychosocial rehabilitation services (Clubhouses) are closed in many parts of Michigan, further limiting care for those in distress or struggling with severe mental illness [99-101]. Due to confined spaces, individuals currently receiving services in residential treatment settings may have elevated risk of COVID-19 infection [1, 52]. Illustrating the contagion risks in these settings, nearly one in five residents of a Michigan adolescent residential treatment 
facility contracted COVID-19 following the infection of a staff member [102]. Once infected, those with severe mental illness may have difficulty accessing COVID-19 treatment due to cognitive impairments and/or mental health discrimination [52].

Survivors of ARDS, which occurs in severe COVID-19 cases, who have previously experienced depression have a three to four times greater risk of prolonged anxiety, depression, or PTSD compared to other ARDS survivors [7•]. Even non-infected individuals with pre-existing depression, anxiety, and other mental health issues are expected to experience elevated worry and anxiety symptomatology due to exacerbation of symptoms by pandemic-related stress [48, 52].

\section{Those at Risk for Domestic Violence}

Rates of domestic violence (DV) and associated traumarelated symptoms are expected to increase during the COVID-19 crisis as a result of rising stress-induced irritability and anger, spiking unemployment rates, and diminishing options for victims to access help or escape perpetrators during stay-home orders $[1,65]$. Already in some Michigan counties, DV reports to law enforcement have doubled, while requests for domestic violence-related emergency shelter have increased by $66 \%$ [1, 66, 67]. The risk of PTSD is six times higher in individuals who have experienced DV compared to other types of trauma, with 64\% developing trauma-related symptoms [68, 69]. Prevalence rates of other mental health conditions are also elevated for victims of DV, including depression (48\%), alcohol use disorder (19\%), and substance use disorders (9\%) [68]. Tragically, but perhaps unsurprisingly, suicidal ideation and attempts are experienced by $18 \%$ of DV victims [69]. When children are exposed to the trauma of witnessing domestic violence, their risk of a later suicide attempt is twice as high as that of unexposed children [98].

\section{Lessons Learned from the 2003 SARS Coronavirus Epidemic}

Although dissimilar in magnitude and case fatality rates, the 2003 SARS coronavirus (SARS-CoV-2) epidemic and the current COVID-19 (initially identified as SARS-CoV-2) pandemic share many similarities [1]. Studies of the aftereffects of the SARS epidemic can, therefore, be used as a model to estimate the impacts of COVID-19 on mental health (Table 2). This model can allow clinicians and public health officials to learn from effective interventions during the SARS epidemic and implement effective interventions to address mental and physical health threats [1].

\section{An Already Stretched Behavioral Health System Infrastructure}

"Access to Behavioral Health Care in Michigan: Final Report" outlined pre-COVID-19 challenges facing Michigan's mental health and substance abuse healthcare infrastructure [103]. As summarized in Table 3, the key findings of this study illustrate the magnitude of untreated mental illness in Michigan, lack of mental health providers and ongoing shortages, and barriers pertaining to access, affordability, and awareness [1]. With the COVID-19 pandemic, these behavioral health needs are further magnified rather than mitigated [1].

Discharge planning in inpatient psychiatric settings is becoming challenging given that programs continuing care for patients in less acute settings are frequently not available, such as partial hospitalization or residential services [104].

Table 2 Impact of SARS-CoV on mental health and effective interventions [1]

\begin{tabular}{|c|c|}
\hline Implications for mental health & Interventions \\
\hline $\begin{array}{l}\text { Highly educated SARS survivors 1-year post-infection } \\
\text { - } 1 / 3 \text { were unable to return to work full-time [14] } \\
\text { - } 60 \% \text { experienced fatigue; } 50 \% \text { had difficulty sleeping [14] } \\
\text { - } 33 \% \text { exhibited significant declines in mental health; } 43 \% \text { received } \\
\text { psychiatric care (mean number of visits } 13 \text { ) [14] } \\
\text { Impact on caregivers } \\
\text { - Exhibited significant decreases in social functioning and mental health } \\
\text { [14] } \\
\text { Suicide rates in Hong Kong after SARS } \\
\text { - } 42 \% \text { increase in suicide rates among older adults for } 2 \text { years after SARS } \\
\text { [15] } \\
\text { - Suicide peak corresponded with infection peak [15] } \\
\text { - Early phases of the SARS epidemic saw increases in persistent depression, } \\
\text { anxiety, panic attacks, psychomotor agitation, psychotic symptoms, } \\
\text { delirium, and suicidality [13] }\end{array}$ & $\begin{array}{l}\text { What worked with SARS } \\
\text { - Multidisciplinary mental health teams supporting patients and healthcare } \\
\text { workers [13] } \\
\text { - Specialized mental health services for COVID-19 patients with comorbid } \\
\text { mental health disorders [13] } \\
\text { - Provision of psychological counseling via tele-technology for patients, } \\
\text { families of patients, and the general public [13] } \\
\text { - Regular screening for depression, anxiety, and suicidality by mental } \\
\text { health workers for COVID-19 patients and healthcare professionals [13] }\end{array}$ \\
\hline
\end{tabular}

Modified and reprinted with permission from [1] 
Table 3 Challenges facing Michigan's mental health and substance abuse infrastructure $[1,103]$

$\begin{aligned} & \text { Untreated mental } \\ & \text { illness }\end{aligned}$
Of the estimated 1.76 million Michigan residents who experience mental illness, 38\% (666,000 individuals) do not receive
Of the estimated 638,000 Michigan residents who experience SUDs, $80 \%$ (510,400 individuals) do not receive SUD treatment.
Anxiety, depression, and alcohol use disorders are the most prevalent psychiatric disorders and also the disorders most likely to
remain untreated. This is particularly true for those experiencing mild-to-moderate symptoms.
Providers and shortages
Behavioral healthcare provider shortages are especially pronounced in Michigan's upper peninsula and the northern half of the
lower peninsula. Of the 36 counties in these regions, 53\% (19 counties) have no psychiatrists and 39\% (14 counties) have no
SUD treatment facilities.
Many Michigan psychiatrists do not participate with insurance plans, limiting access to care.
awareness
Among those with untreated mental illness, the top self-reported barrier to treatment was "Couldn't afford costs" (40\%).
Lack of awareness of treatment options was endorsed by 22\%.
After readiness for change, the most frequent self-reported barriers to SUD treatment were affordability (27\%) and
unawareness of treatment options (19\%).
Those with Medicaid insurance were least likely to receive needed mental health treatment (49\%).
For SUDs, the privately insured were most likely to remain untreated (87\%).
Among individuals with private insurance, those in high-deductible insurance plans were least likely to receive treatment.
Psychiatric patients with high acuity symptoms or medical complications often have prolonged waits for transfers to
appropriate treatment settings, resulting in frequent emergency department "boarding" of psychiatric patients.
Except for psychiatric urgent care settings, wait times for appointments with psychiatrists can span weeks to months

\section{Immediate Strategic Actions Needed for Behavioral Health System Infrastructure}

From a statewide behavioral health provider's point-of-view, we have outlined below strategic actions to address the mental health needs associated with the COVID-19 pandemic and its aftermath [1]. These actions should be implemented immediately to prepare for the expected upsurge of behavioral health needs in the ensuing months [1].

\section{Improve Behavioral Health Access Through Awareness, Affordability, and Technology}

\section{Ongoing Investment in Telehealth}

Teletherapy and telepsychiatry are essential strategies to address currently underserved communities in Michigan, as well as meet the projected COVID-19 rise in mental health needs [1]. It is encouraging that many providers are offering virtual behavioral health services, and many Michigan payers are reimbursing tele-services with copays and deductibles waived for these behavioral health services [1]. The importance of securing payment for telehealth is underscored by Great Lakes ambulatory clinics identifying reimbursement as the greatest barrier to implementing or expanding telehealth services [93].

We advocate that Michigan take these additional steps:

- Extension of payer reimbursement of tele-behavioral health services through June 2021, if not longer [1]. As summarized above, Michigan residents with mental health issues are at high risk of COVID-19 infection and mental health symptom exacerbation [1, 48, 51-53]. Individuals who survive severe complications of COVID-19 will likely experience prolonged and serious mental health symptoms and require continued mental health treatment [7•] This extension will allow high-risk Michigan residents to continue to access mental health services, despite physical distance, social distancing, or medical complications [1].

- Expand behavioral health capability and capacity throughout the state by supporting public and private foundation grants [1]. For example, almost $\$ 3$ million was recently awarded to behavioral health organizations in Michigan by The Michigan Health Endowment Fund and four other partners [1].

\section{Significantly Improve Public Awareness of Mental Health and Substance Use Disorder Treatment Options and Increase Individuals' Recognition of the Importance of Treatment Engagement Before Further Exacerbation of Mental Health Symptoms or Problematic Substance Use}

The institutions and care providers where behavioral health problems are often first detected and referrals for treatment made - such as primary care offices, schools and universities, community health centers, emergency departments, and places of worship - are currently closed or functioning below typical capacity [1]. As a result, symptoms of mental illness and SUDs remain undetected, critical treatment referrals are not being made, and stressors leading to suicide and increased mental illness/SUD symptoms are rising simultaneously. To mitigate these compounding behavioral health risks, the following strategies are recommended: 
- Widely market tele-behavioral health options currently available in Michigan to address awareness barriers to accessing treatment [1].

- Commence statewide communication urging individuals to seek behavioral health assistance when experiencing mental health symptoms and highlighting the availability of tele-behavioral health services [1]. This message should be delivered from Michigan's highest authorities and echoed throughout the state by public and private organizations, community leaders, and care providers [1].

- Provide education to residents and staff of long-term care facilities about the availability and effectiveness of teletherapy in treating depression and anxiety in older adults [105]. Individuals in these settings may particularly benefit from evidence-based teletherapy due to their elevated risk of COVID-19 exposure and complications, social isolation and disrupted daily activities following protective executive orders, and elevated risk for suicide.

- Educate the general public on how to identify mental illness signs or symptoms, check in with others, and support each other in accessing treatment.

\section{Match Behavioral Health Capacity With Statewide Needs}

To assist hospitals at maximum capacity due to COVID-19 cases, the Michigan Department of Health and Human Services has applied "COVID-19 Relief Healthcare Facility" infrastructure to enact a statewide COVID-19 Load Balancing Plan that enables overwhelmed hospitals to identify hospitals with capacity and transfer patients to these "relief hospitals" when needed [1]. If behavioral health needs quickly swell, as predicted in this report, it may be necessary to temporarily expand the Relief Healthcare Facility infrastructure to match behavioral health capacity with statewide need [1]. Michigan should also take the following steps:

- Utilize hospital "bedboard" monitoring tools, such as EMResource [106], to provide up-to-date statewide snapshots of inpatient and partial psychiatric hospitals' available capacity [1].

- Implement a statewide treatment resource tracking tool, such as OpenBeds [107], to allow for the rapid identification of available inpatient, outpatient, and telehealth treatment options for mental health and SUD difficulties [1].

- Ensure access to these tools is easy-to-find and promote usage by services such as United Way, the National Suicide Prevention Hotline, and Michigan's mental health "warmline" [1].

- Establish and fund 365/24/7 call centers that can quickly connect consumers and referring providers to behavioral health services [1].

\section{Waive Behavioral Health Copays and Deductibles for the Short Term}

As summarized above, perceived unaffordability is a substantial barrier to mental health and SUD treatment initiation [1, 103]. Due to the COVID-19 pandemic, many Michigan insurance companies have waived copays and deductibles for telehealth treatment of behavioral health needs [1]. We recommend these waivers continue through June of 2021, with expansion to in-person behavioral treatment once it resumes in Michigan [1]. This recommendation is consistent with existing policies promoting access to primary care.

\section{Further Development of Behavioral Health Workforce}

Increasing access to psychiatrists, psychologists, social workers, and other mental health clinicians is paramount to meet the rising behavioral health needs in Michigan. Recruiting and training entry-level and professional staff will be necessary, with emphasis placed on treating those experiencing loss, trauma, substance use disorders, and/or suicidal ideation or behaviors. The ongoing shortage of behavioral health providers in Michigan is a long-term problem beyond the scope of this report. However, several steps could be taken immediately to begin addressing this issue.

\section{Retraining Existing Providers}

Many mental health clinicians lack confidence and competence in providing effective treatment for suicidality, often as a result of few graduate training programs in counseling, marriage and family therapy, social work, and psychology providing formal training in empirically based suicide prevention treatments [108, 109]. Fortunately, clinical training in evidence-based suicide prevention practices and interventions is increasingly available. Some of these evidence-based interventions and treatment approaches include the following: the Columbia Suicide Severity Rating Scale (C-SSRS) for consistently assessing suicide risk [110]; Collaborative Assessment and Management of Suicidality (CAMS), a clinical framework for assessing, treating, and managing suicide risk [111]; Cognitive Behavioral Therapy for Suicide Prevention (CBT-SP), which uses a relapse prevention approach to reduce suicide risk [112]; and Dialectical Behavior Therapy (DBT), an intensive treatment modality designed for individuals with chronic suicidal thoughts, behaviors, and attempts that has demonstrated effectiveness in reducing suicide attempts by two-thirds [113]. Incorporating these interventions and other best practices for suicide prevention, SAMHSA recommended Zero Suicide framework as a systemic approach to evidence-based suicide prevention and quality improvement and has reduced suicide rates by $64-75 \%$ in systems where it has been implemented [114]. The training costs 
and time requirements of these trainings and the implementation of the Zero Suicide framework, however, can be difficult for individual clinicians and behavioral healthcare organizations to absorb [1].

\section{Entry-Level Recruitment and Training}

Prior to the pandemic, Michigan faced a shortage of qualified candidates to fill vital psychiatric and nurse technician roles. This ongoing need could help address the rise in unemployment if displaced workers can receive the skills training necessary to provide valuable, frontline mental health care [1]. For patients in a mental health crisis, it is crucial that behavioral health employees, including non-clinicians, be adept in recognizing, assessing, and intervening to address suicide risk. To equip entry-level direct care employees with these critical skills, a limited number of research-informed trainings have been developed and validated, including Question, Persuade, Refer (QPR) [115]; Applied Suicide Intervention Skills Training (ASIST) [116]; and Assessing and Managing Suicide Risk (AMSR) for direct care staff [117]. These trainings have demonstrated effectiveness in improving staff members' abilities to recognize suicide warning signs, evaluate suicide risk, engage at-risk individuals in treatment, and produce clinical outcomes, such as increased felt hope and decreased suicidality in care recipients $[115,116]$. Although the cost of these trainings for a single employee is minimal, the cumulative cost across a behavioral healthcare agency can present a significant barrier to necessary staff training.

It is, therefore, recommended that communities and statewide leaders collaborate to ensure funding and training infrastructure are provided that ensures easy access to training in these life-saving interventions for all behavioral healthcare employees and clinicians. Such an investment could help care providers meet the rising mental health needs and save many Michigan lives through effective suicide prevention [1].

\section{Addressing Critical Gaps in Behavioral Health Infrastructure}

Michigan has a long-standing problem with boarding psychiatric patients in emergency departments due to the difficulty in providing access to appropriate care settings [1]. This issue is particularly problematic for psychiatric patients with COVID19 because psychiatric hospitals are not equipped or staffed to safely and effectively care for patients with medical complications arising from this highly infectious disease [1]. Patients with high psychiatric acuity can also be particularly difficult to place due to the increased staffing needs required to manage the most severe or aggressive symptoms, provide increased monitoring, and alter interventions and procedures in order to ensure the safety of the patient and others on the unit. One potential solution is to implement a Psychiatric
Intensive Care enhanced per diem rate to improve access to costly care required for these difficult-to-place patients, thereby decreasing the burden on emergency departments and acute care hospitals [1].

Michigan treatment settings received COVID-19 resources through a variety of methods. Similar to other hospitals throughout the nation, general resource disbursement was made to those facilities based on how much Medicaid or Medicare revenue was received pre-COVID. Some funds through the CARES Act were distributed to the areas hardest hit by COVID-19, specifically southeast Michigan, rural areas, and Federally Qualified Health Centers. Resources that flowed through FEMA were distributed to state, county, and government agencies. Some of those funds have been made available to private non-profits through a grant funding process at the discretion of the agency.

\section{Additional Mental Health Services}

Due to the COVID-19 crisis, an increased number of treatment and support groups will be needed for individuals quarantined at home, caregivers, COVID-19 healthcare providers, mental health clinicians, and LGBTQ individuals [1]. Behavioral health services and coverage will also need to expand to include case management, care coordination with external providers, psychoeducational classes, and transition clinics that can help address gaps in care between psychiatric inpatient settings and outpatient treatment [1]. Expansion of these services and insurance coverage of them can help address gaps in the mental health treatment continuum, enable existing mental healthcare systems to adapt to the predicted spike in behavioral health care needs, and ensure suicidal individuals are immediately able to access critical evidencebased care for suicide prevention [1].

\section{Conclusion}

Just as the initial response to the COVID-19 pandemic focused on physical health, the subsequent response needs to address the mental health of Michigan residents [1]. Improving and increasing access to behavioral health care by means of awareness, affordability, and technology; training and developing the workforce; and fixing gaps in mental health infrastructure will be essential to minimize the impact of the COVID-19 pandemic on behavioral health in Michigan [1]. These actions need to be implemented immediately to prepare for the expected "surge" of behavioral health needs in the ensuing months and to prevent a "double tragedy" from pandemic-related suicide deaths [1]. 
Acknowledgments The authors of "Preparing Michigan for the Behavioral Health Impact of COVID-19. 2020 Apr 26" [1] granted permission to modify and reproduce Tables 1 and 2 for this manuscript.

\section{Compliance with Ethical Standards}

Conflict of Interest Evonne Edwards, Carol A. Janney, Amy Mancuso, Heide Rollings, Amy VanDenToorn, Mariah DeYoung, Scott Halstead, and Mark Eastburg declare that they have no conflicts of interest.

Human and Animal Rights and Informed Consent This article does not contain any studies with human or animal subjects performed by any of the authors.

\section{References}

Papers of particular interest, published recently, have been

highlighted as:

- Of importance

•- Of major importance

1. Edwards E, Mancuso A, Rollings H, VanDenToorn A, DeYoung M, Halstead S, Eastburg M. Preparing Michigan for the behavioral health impact of COVID-19.2020 Apr 26. Available from https:// www.pinerest.org/media/Preparing-Michigan-for-the-BehavioralHealth-Impact-of-COVID-19-Report.pdf. Accessed 5 May 2020.

2. State of Michigan. Coronavirus [Internet]. 2020. Available from: https://www.michigan.gov/coronavirus/. Accessed 4 Aug 2020.

3. Grant MJ, Booth A. A typology of reviews: an analysis of 14 review types and associated methodologies. Health Inf Libr J. 2009;26(2):91-108. https://doi.org/10.1111/j.1471-1842.2009. 00848.x.

4.• Wang C, Pan R, Wan X, Tan Y, Xu L, Ho CS, Ho RC. Immediate psychological responses and associated factors during the initial stage of the 2019 coronavirus disease (COVID-19) epidemic among the general population in China. Int $\mathrm{J}$ Environ Res Public Health. 2020;17(5):1729. Available from: https://doi.org/10.3390/ ijerph17051729. Accessed 8 May 2020. A large cross-sectional survey study of the psychological impact of the COVID-19 epidemic within the general population in China.

5. Servick K. For survivors of severe COVID-19, beating the virus is just the beginning. Science [Internet]. $2020 \mathrm{Apr} 8$. Available from: https://www.sciencemag.org/news/2020/04/survivors-severecovid-19-beating-virus-just-beginning. Accessed 17 Apr 2020.

6. Bailey SP. Alcoholics Anonymous, struggling to reach new members during the shutdown, expects a surge. Washington Post [Internet]. 2020 Jun 12. Available from: https://www. washingtonpost.com/religion/2020/06/12/alcoholics-anonymousstruggling-reach-new-members-during-shutdown-expects-surge/. Accessed 22 Jul 2020.

7. Bienvenu OJ, Friedman LA, Colantuoni E, et al. Psychiatric symptoms after acute respiratory distress syndrome: a 5-year longitudinal study. Intensive Care Med. 2018;44:38-47. https://doi. org/10.1007/s00134-017-5009-4. A prospective cohort study examining the prolonged impacts of ARDS on anxiety, depression, and PTSD symptoms.

8.• Reger MA, Stanley IH, Joiner TE. (2020). Suicide mortality and coronavirus disease 2019-a perfect storm? JAMA Psychiatry. Published online April 17, 2020. https://jamanetwork.com/ journals/jamapsychiatry/fullarticle/2764584. Accessed 8 May 2020. This brief article reviews the impact of COVID-19 on known predictors of suicide and recommends interventions to reduce suicide risk.

9. Ahmedani BK, et al. Major physical health conditions and risk of suicide. Am J Prev Med. 2017;53(3):308-15. A large casecontrol study assessing the odds of suicide for individuals with various physical health conditions.

10. Centers for Disease Control and Prevention. Interim clinical guidance for management of patients with confirmed coronavirus disease (COVID-19). 2020. Available from http://www.cdc.gov/ coronavirus/2019-ncov/hcp/clinical-guidance-managementpatients.html. Accessed 17 Apr 2020.

11. Seladi-Schulman J. COVID-19 vs. SARS: how do they differ? Healthline [Internet]. 2020 Apr 2. Available from http://www. healthline.com/health/coronavirus-vs-sars. Accessed $17 \mathrm{Apr}$ 2020.

12. Meng L, Qiu H, Wan L, Ai Y, Xue Z, Guo Q, Deshpande R, Zhang L, Meng J, Tong C, Liu H, Xiong L. Intubation and ventilation amid the COVID-19 outbreak: Wuhan's experience. Anesthesiology. 2020. https://doi.org/10.1097/ALN. 0000000000003296 . Accessed 8 May 2020.

13. Xiang Y, et al. Timely mental health care for the 2019 novel coronavirus outbreak is urgently needed. Lancet Psychiatry. 2020;7(3):228-9. https://doi.org/10.1016/S2215-0366(20)300468 .

14. Tansey CM, Louie M, Loeb M, et al. One-year outcomes and health care utilization in survivors of severe acute respiratory syndrome. Arch Intern Med. 2007;167(12):1312-20. https://doi.org/ 10.1001/archinte.167.12.1312.

15. Cheung YT, Chau PH, Yip PS. A revisit on older adults suicides and severe acute respiratory syndrome (SARS) epidemic in Hong Kong. Int J Geriatr Psychiatry. 2007;23(12):1231-8. https://doi. org/10.1002/gps.2056.

16. Unacast. Social Distancing Scoreboard. 2020. Available from: http://www.unacast.com/covid19/social-distancing-scoreboard. Accessed 17 Apr 2020.

17. Calati R, Ferrari C, Brittner M, Oasi O, Olié E, Carvalho AF, et al. Suicidal thoughts and behaviors and social isolation: a narrative review of the literature. J Affective Disorders. 2019;245:653-67. https://doi.org/10.1016/j.jad.2018.11.022. A review of the impacts of social isolation and loneliness in various situations on suicidal ideation and suicide attempts.

18. Brooks SK, Webster RK, Smith LE, Woodland L, Wessely S, Greenberg N, et al. The psychological impact of quarantine and how to reduce it: rapid review of the evidence. Lancet. 2020;395(10227):912-20. https://doi.org/10.1016/S01406736(20)30460-8. A review of studies examining the negative psychological effects of quarantine.

19. Liu JJ, Bao Y, Huang X, Shi J, Lu L. Mental health considerations for children quarantined because of COVID-19. The Lancet Child \& Adolescent Health [Internet]. 2020 Mar 27. https://doi.org/10. 1016/S2352-4642(20)30096-1. Accessed 8 May 2020.

20. U.S. Department of Labor. The employment situation-April 2020. 2020 May 8. Available from: https://www.bls.gov/news.release/ empsit.nr0.htm. Accessed 8 May 2020.

21. U.S. Department of Labor. Unemployment insurance weekly claims. 2020 May 7. Available from: https://www.dol.gov/ui/ data.pdf. Accessed 8 May 2020.

22. Oyesanya M, Lopez-Morinigo J, Dutta R. Systematic review of suicide in economic recession. World J Psychiatr. 2015;5(2):243 54. https://doi.org/10.5498/wjp.v5.i2.243.

23. Dom G, Samochowiec J, Evans-Lacko S, Wahlbeck K, Van Hal G, McDaid D. The impact of the 2008 economic crisis on substance use patterns in the countries of the European Union. Int J Environ Res Public Health. 2016;13(1):122.

24. Richardson T, Elliott P, Roberts R. The relationship between personal unsecured debt and mental and physical health: a systematic 
review and meta-analysis. Clin Psychol Rev. 2013;33(8):114862. https://doi.org/10.1016/j.cpr.2013.08.009.

25. Hindi S. "Like the rug was ripped out from under me": the mental health costs of coronavirus. The Denver Post [Internet]. Denver; 2020 Apr 12. Available from http://www.denverpost.com/2020/ 04/12/mental-health-colorado-coronavirus-covid/. Accessed 8 May 2020.

26. Cunningham A. Suicide dangers grow during COVID-19 pandemic. 13 on Your Side [Internet]. 2020. Available from http:// www.wzzm13.com/article/news/local/morning-features/suiciderisks-grow-during-pandemic/69-05657859-d404-44ad-bf87c70dad3c6671. Accessed 17 Apr 2020.

27. Hong Kong Jockey Club Center for Suicide Research and Prevention. 1981-2018 Hong Kong Suicide Statistics [Internet]. 2020. Available from https://csrp.hku.hk/statistics/. Accessed 9 May 2020.

28. Centers for Disease Control and Prevention (CDC). Suicide rising across the US: more than a mental health concern. Vital Signs [Internet]. 2018 Jun 7. Available from: https://www.cdc.gov/ vitalsigns/pdf/vs-0618-suicide-H.pdf. Accessed 8 May 2020.

29. Phillips, JA, Nugent, CN. Suicide and the Great Recession of 2007-2009: the role of economic factors in the 50 U.S. states. Social Science \& Medicine. 2014;116: 22-31. https://doi.org/10. 1016/j.socscimed.2014.06.015

30.• Centers for Disease Control and Prevention. CDC wonder underlying cause of death 1999-2018. 2020. Available from: https:// wonder.cdc.gov/. Accessed 17 Apr 2020. A dataset from the CDC that includes annual counts of suicide deaths by state and county for years 1999-2018.

31. Suicide Prevention Resource Center. Treating suicidal patients during COVID-19: best practices and telehealth [Webinar]. 2020 Apr 14. Available from: http://zerosuicide.edc.org/webinars-andpresentations/webinar-treating-suicidal-patients-during-covid-19best-practices-and. Accessed 17 Apr 2020.

32. Mehrota A, Chernew M, Linetsky D, Hatch H, Cutler D. What impact has COVID-19 had on outpatient visits? To the Point [blog]. Commonwealth Fund. 2020. Available from https://doi. org/10.26099/ds9e-jm36. Accessed 8 May 2020.

33. Mann JJ, Apter A, Bertolote J, Beautrais A, Currier D, Haas A, et al. Suicide prevention strategies: a systematic review. JAMA. 2005;294(16):2064-74.

34. Jensen JF, Thomsen T, Overgaard D, Bestle MH, Christensen D, Egerod I. Impact of follow-up consultations for ICU survivors on post-ICU syndrome: a systematic review and meta-analysis. Intensive Care Med. 2015;41(5):763-75. https://doi.org/10.1007/ s00134-015-3689-1.

35. Lai J, Ma S, Wang Y, Cai Z, Hu J, Wei N, et al. Factors associated with mental health outcomes among health care workers exposed to coronavirus disease 2019. JAMA Netw Open. 2020;3(3): e203976. https://doi.org/10.1001/jamanetworkopen.2020.3976.

36. Lin H, Lai C, Perng, et al. Insomnia as an independent predictor of suicide attempts: a nationwide population-based retrospective cohort study. BMC Psychiatry. 2018;18:117.

37. Lavoice O. 'A lot of first-time buyers': gun sales surge amid COVID-19 outbreak. Q13Fox [Internet]. 2020 Mar 25. Available from https://q13fox.com/2020/03/25/local-gun-sales-see-massiveincrease-amid-covid-19-outbreak/. Accessed 17 Apr 2020.

38. Pane L. Gun background checks smash records amid coronavirus fears. Associate Press [Internet]. 2020 Apr 1. Available from https:// apnews.com/64b328e6d0559e13dd7ef6e2ee0663f9. Accessed 17 Apr 2020.

39. Anglemyer A, Horvath T, Rutherford G. The accessibility of firearms and risk for suicide and homicide victimization among household members: a systematic review and meta-analysis. Ann Intern Med. 2014;160(20):101-10.
40. Lewiecki EM, Miller SA. Suicide, guns, and public policy. Am J Public Health. 2013;103(1):27-31.

41. National Institute of Mental Health. Suicide [Internet]. 2019. Available from https://www.nimh.nih.gov/health/statistics/ suicide.shtml. Accessed 8 May 2020.

42. Katz-Wise SL, Rosario M, Tsappis M. Lesbian, gay, bisexual, and transgender youth and family acceptance. Pediatr Clin N Am. 2016;63(6):1011-25.

43. di Giacomo E, Krausz M, Colmegna F, Aspesi F, Clerici M. Estimating the risk of attempted suicide among sexual minority youths: a systematic review and meta-analysis. JAMA Pediatr. 2018;172(12):1145-52. https://doi.org/10.1001/jamapediatrics. 2018.2731 .

44. Hottes TS, Bogaert L, Rhodes AE, Brennan DJ, Gesink D. Lifetime prevalence of suicide attempts among sexual minority adults by study sampling strategy: a systematic review and meta-analysis. Am J Public Health. 2016;106(5):e1-e12. https://doi. org/10.2105/AJPH.2016.303088.

45. Kaniuka A, Pugh KC, Jordan M, Brooks B, Dodd J, Mann AK, et al. Stigma and suicide risk among the LGBTQ population: are anxiety and depression to blame and can connectedness to the LGBTQ community help? J Gay Lesbian Ment Health. 2019;23(2):205-20. A study examining the moderating impact of LGBTQ community connectedness on the relationship between stigma and suicidal behaviors, anxiety, and depression amongst LGBTQ individuals.

46. Parra LA, Bell TS, Benibgui M, Helm JL, Hastings PD. The buffering effect of peer support on the links between family rejection and psychosocial adjustment in LGB emerging adults. J Soc Pers Relatsh. 2018;35(6):854-71.

47. Ryan C, Huebner D, Diaz RM, Sanchez J. Family rejection as a predictor of negative health outcomes in white and Latino lesbian, gay, and bisexual young adults. Pediatrics. 2009;123(1):346-52.

48. Druss BG. Addressing the COVID-19 pandemic in populations with serious mental illness. JAMA Psychiatry. 2020 Apr 3. https://doi.org/ 10.1001/jamapsychiatry.2020.0894. Accessed 17 Apr 2020.

49. Merritt Hawkins and The Physicians Foundation. Physicians and COVID-19: a survey examining how physicians are being affected by and are responding to the coronavirus pandemic [Internet]. 2020 Apr. Available from https://www.merritthawkins.com/ uploadedFiles/Corona_Physician_Survey_Merritt_Hawkins_ Report.pdf. Accessed 8 May 2020.

50. Gold KJ, Sen A, Schwenk TL. Details on suicide among US physicians: data from the National Violent Death Reporting System. Gen Hosp Psychiatry. 2013;35(1):45-9. https://doi.org/ 10.1016/j.genhosppsych.2012.08.005.

51. Xiang Y, Jin Y, Cheung T. Joint international collaboration to combat mental health challenges during the coronavirus disease 2019 pandemic. JAMA Psychiatry. 2020. https://doi.org/10.1001/ jamapsychiatry.2020.1057.

52. Yao H, Chen J, Xu Y. Patients with mental health disorders in the COVID-19 epidemic. Lancet Psychiatry. 2020;7(4):e21. https:// doi.org/10.1016/S2215-0366(20)30090-0.

53. Kiecolt-Glaser J, McGuire L, Robles TF, Glaser R. Psychoneuroimmunology: psychological influences on immune function and health. J Consult Clin Psychol. 2002;70(3):537-47. https://doi.org/10.1037/0022-006X.70.3.537.

54. Gustafson I. Alcohol sales see significant growth amid COVID19. C Store Decisions [Internet]. 2020. Available from http:// www.cstoredecisions.com/2020/03/27/alcohol-sales-seesignificant-growth-amid-covid-19/. Accessed 17 Apr 2020.

55. Volkow ND. Collision of the COVID-19 and addiction epidemics. Annals of Internal Medicine. 2020. https://doi.org/10.7326/M201212. Accessed 17 Apr 2020. A brief review of the unique impacts of COVID-19 on individuals with substance use disorders. 
56. Kleiman EM, Beaver JK. A meaningful life is worth living: meaning in life as a suicide resiliency factor. Psychiatry Res. 2013;210(3):934-9.

57. Kaplan MS, McFarland BH, Huguet N, Conner K, Caetano R, Giesbrecht N, et al. Acute alcohol intoxication and suicide: a gender-stratified analysis of the National Violent Death Reporting System. Injury Prevention. 2013;19:38-43.

58. Inskip $\mathrm{H}$, Harris $\mathrm{C}$, Barraclough $\mathrm{B}$. Lifetime risk of suicide for affective disorder, alcoholism, and schizophrenia. BJPsych. 1998;172(1):35-7.

59. Stone DM, Simon TR, Fowler KA, Kegler SR, Yuan K, Holland $\mathrm{KM}$, et al. Vital signs: trends in state suicide rates-United States, 1999-2016 and circumstances contributing to suicide-27 states, 2015. CDC Morbidity and Mortality Weekly Report. 2018;67(22):617-24.

60. DeVille DC, Whalen D, Breslin FJ, Morris AS, Khalsa SS, Paulus MP, et al. Prevalence and family-related factors associated with suicidal ideation, suicide attempts, and self-injury in children aged 9 to 10 years. JAMA Netw Open. 2020;3(2):e1920956. https:// doi.org/10.1001/jamanetworkopen.2019.20956.

61. Conrad-Hiebner A, Scanlon E. The Economic conditions of child physical abuse: a call for a national research, policy, and practice agenda. Fam Soc. 2015;96(1):59-66. https://doi.org/10.1606/ 1044-3894.2015.96.8.

62. Raissian KM. Does unemployment affect child abuse rates? Evidence from New York state. Child Abuse Neglect. 2015;48: 1-12. https://doi.org/10.1606/1044-3894.2015.96.8.

63. Gordon JA. Coping with coronavirus: support for the autism community. National Institute of Mental Health. 2020. Available from http://www.nimh.nih.gov/about/director/messages/2020/copingwith-coronavirus-support-for-the-autism-community.shtml?utm source $=$ rss_readers\&utm_medium $=$ rss\&utm_campaign $=r s s$ summary. Accessed 17 Apr 2020

64. SPARK: Simons Foundation Powering Autism Research for Knowledge. Impact of COVID-19 on families and children with autism [Internet]. 2020. Available from d2dxtcm9g2oro2. cloudfront.net/wp-content/uploads/2020/04/03195500/sparkcovid-survey-results.pdf. Accessed 17 Apr 2020. A survey study of parents and caregivers of children with ASD regarding the impact of the COVID-19 pandemic and social distancing on mental health symptoms.

65. World Health Organization. COVID-19 and violence against women: what the health sector/system can do. 2020 Apr 7. Available from https://apps.who.int/iris/bitstream/handle/10665/ 331699/WHO-SRH-20.04-eng.pdf. Accessed 17 Apr 2020.

66. Stateside staff. Domestic violence related police calls on the rise amid COVID-19 stay at home order, says advocate. Michigan Radio [Internet]. 2020 Apr 13. Available from http://www.michiganradio. org/post/domestic-violence-related-police-calls-rise-amid-covid-19stay-home-order-says-advocate. Accessed 17 Apr 2020.

67. Szatkowski A. West Michigan domestic violence cases increase during COVID-19 outbreak. Fox17 [Internet]. 2020. Available from http://www.fox17online.com/homepage-showcase/westmichigan-domestic-violence-cases-increase-during-covid-19outbreak. Accessed 17 Apr 2020.

68. Roberts AL, Gilman SE, Breslau J, Breslau N, Koenen KC. Race/ethnic differences in exposure to traumatic events, development of post-traumatic stress disorder, and treatment-seeking for post-traumatic stress disorder in the United States. Psychol Med. 2011;41(1):71-83.

69. Golding JM. Intimate partner violence as a risk factor for mental disorders: a meta-analysis. J Fam Violence. 1999;14(2):99-132.

70. Altarum. COVID-19 survey results [Internet]. 2020 Apr 9. Available from: https://altarum.org/covid/results. Accessed 19 Jul 2020.
71. Kaiser Family Foundation. Mental health in Michigan. Mental Health and Substance Use State Fact Sheets [Internet]. KFF. 2020. Available from: https://www.kff.org/statedata/mental-health-andsubstance-use-state-fact-sheets/. Accessed 27 Jul 2020.

72. Lawrence RE, Oquendo MA, Stanley B. Religion and suicide risk: a systematic review. Arch Suicide Res. 2016;20(1):1-21.

73. Greenfield EA, Vaillant GE, Marks NF. Do formal religious participation and spiritual perceptions have independent linkages with diverse dimensions of psychological well-being? J Health Soc Behav. 2009;50(2):196-212.

74. Wingbland A. Marijuana, alcohol use way up during COVID-19 outbreak. The Voice [Internet]. 2020. Available from http://www. voicenews.com/news/coronavirus/marijuana-alcohol-use-wayup-during-covid-19-outbreak/article_acd67bf2-89c7-55c9-8032fd58983e64dc.html. Accessed 17 Apr 2020.

75. McCall A. $20 \%$ increase in patients seeking substance abuse treatment [Internet]. WXMI. 2020 May 2. Available from: https://www. fox 17 online.com/news/local-news/grand-rapids/20-increase-inpatients-seeking-substance-abuse-treatment. Accessed 19 Jul 2020.

76. Substance Abuse and Mental Health Services Administration. Results from the 2018 national survey on drug use and health: detailed tables. Rockville, MD: Center for Behavioral Health Statistics and Quality, Substance Abuse and Mental Health Services Administration; 2019. Retrieved from https://www. samhsa.gov/data/. Accessed 22 Jul 2020.

77. American Society of Addiction Medicine (ASAM). COVID-19 infection mitigation in residential treatment facilities. 2020 Jun 2020. Available from: https://www.asam.org/QualityScience/covid-19-coronavirus/infection-mitigation-in-residentialtreatment-facilities. Accessed 22 Jul 2020.

78. State of Michigan. Whitmer - Executive Order 2020-136 (COVID-19) [Internet] . 2020 Jun 26. Available from: https:// www.michigan.gov/whitmer/0,9309,7-387-90499 90705$533076 \% 2 \mathrm{D} \% 2 \mathrm{D}, 00 . \mathrm{html}$. Accessed $21 \mathrm{Jul} 2020$

79. Taylor KH. Battered by COVID-19, substance abuse help agencies face 'unprecedented' need. Detroit Free Press [Internet]. 2020 July 6. Available from: https://www.freep.com/story/news/local/ michigan/2020/07/06/covid-19-mental-health-clinicsunprecedented-need/3171562001/. Accessed 22 Jul 2020.

80. Barkil-Oteo A. Collaborative care for depression in primary care: how psychiatry could "troubleshoot" current treatments and practices. Yale J Biol Med. 2013;86:139-46.

81. The Joint Commission. The Joint Commission Update: COVID19 [unpublished meeting slides]. Behavioral Health Care Accreditation Advisory Council Meeting. 2020 Apr 30.

82. Michigan Department of Health \& Human Services (MDHHS) Division for Vital Records \& Health Statistics. Monthly Death Counts [Internet]. Available from: https://www.mdch.state.mi.us/ osr/Provisional/MontlyDxCounts.asp. Accessed 19 Jul 2020.

83. Baldas T. ER visits plummet amid pandemic: 'We know more people are dying at home'. Bridge Magazine [Internet]. Available from: https://www.bridgemi.com/michigan-healthwatch/er-visits-plummet-amid-pandemic-more-people-are-dyinghome. Accessed 19 Jul 2020.

84. Michigan Department of Health and Human Services. State's chief medical executive urges Michiganders not to delay emergency care: data shows alarming increase in out of hospital deaths between March and May 2020. 2020 July 2. Available from: https://www.michigan.gov/som/0,4669,7-192-29942_34762$533471 \% 2 \mathrm{D} \% 2 \mathrm{D}, 00 . \mathrm{html}$. Accessed $22 \mathrm{Jul} 2020$.

85. Bashar FR, Vahedian-Azimi A, Hajiesmaeili M, Salesi M, Farzanegan B, Shojaei S, et al. Post-ICU psychological morbidity in very long ICU stay patients with ARDS and delirium. J Crit Care. 2018;43:88-94. https://doi.org/10.1016/j.jcrc.2017.08.

86. American College of Cardiology. COVID-19 clinical guidance for the cardiovascular care team [Internet]. 2020. Available from 
http://www.acc.org/ /media/Non-Clinical/Files-PDFs-Excel-MSWord-etc/2020/02/S20028-ACC-Clinical-Bulletin-Coronavirus. pdf. Accessed 17 Apr 2020.

87. Turner A. Health care sheds 43,000 jobs in March, the biggest loss in at least three decades [Internet]. Altarum. 2020 Apr 3. Available from: https://altarum.org/news/health-care-sheds-43000-jobsmarch-biggest-loss-least-three-decades. Accessed 19 Jul 2020.

88. American Hospital Association. Hospitals and health systems face unprecedented financial pressures due to COVID-19. AHA [Internet]. 2020 May. Available from: https://www.aha.org/ guidesreports/2020-05-05-hospitals-and-health-systems-faceunprecedented-financial-pressures-due. Accessed 22 Jul 2020.

89. Greene J. Mich. health systems garner more than $\$ 4.4$ billion in COVID-19 relief funding. Modern Healthcare [Internet]. 2020 Jun 29. Available from https://www.modernhealthcare.com/ finance/mich-health-systems-garner-more-44-billion-covid-19relief-funding. Accessed 22 Jul 2020.

90. Erb R. Michigan hospitals: federal coronavirus funds not enough, we need more. Detroit Free Press [Internet]. 2020 Jul 1. Available from: https://www.freep.com/story/news/local/michigan/2020/07/ 01/michigan-hospitals-federal-funds-money-coronavirus/ 5355451002/. Accessed 22 Jul 2020.

91. Shamus KJ, Dixon J. Detroit's Henry Ford Health System furloughs 2,800 workers [internet]. 2020 Apr 22. Available from: https://www.freep.com/story/news/local/michigan/detroit/2020/ 04/22/detroit-henry-ford-health-system-furloughs-2800-workers/ 3008929001/

92. Baldas T. Beaumont ER doctors agree to pay cuts, leaves of absence amid COVID-19 crisis [Internet]. Detroit Free Press. 2020 Apr 27. Available from: https://www.freep.com/story/news/local/ michigan/2020/04/27/beaumont-er-doctors-pay-cuts-coronavirus/ 3033172001/. Accessed 22 Jul 2020.

93. Altarum. COVID-19 ambulatory clinic survey [Internet]. Available from: https://data.surveygizmo.com/r/321870 5e99b794815de4.44267546. Accessed 19 Jul 2020.

94. Wheaton B. Michigan's aging adults, persons with disability can take survey to tell MDHHS how to better meet COVID-19 needs. 2020 July 6. Available from: https://www.michigan.gov/som/ 0,4669,7-192-29942 34762-533575\%2D\%2D,00.html. Accessed 22 Jul 2020.

95. State of Michigan. Whitmer - Executive Order 2020-148: Enhanced protections for residents and staff of long-term care facilities during the COVID-19 pandemic [Internet]. 2020 Jul 13. Available from: https://www.michigan.gov/whitmer/ 0,9309,7-387-90499_90705-534172\%2D\%2D,00.html. Accessed 21 Jul 2020.

96. Czeisler CA, Gooley JJ. Sleep and circadian rhythms in humans. Cold Spring Harb Symp Quant Biol. 2007 Jan 1;72:579-97.

97. Kim JH, Duffy JF. Circadian rhythm sleep-wake disorders in older adults. Sleep Med Clin. 2018 Mar 1;13(1):39-50.

98. Dube SR, Anda RF, Felitti VJ, Chapman DP, Williamson DF, Giles WH. Childhood abuse, household dysfunction, and the risk of attempted suicide throughout the life span: findings from the adverse childhood experiences study. JAMA. 2001;286(24): 3089-96. https://doi.org/10.1001/jama.286.24.3089.

99. Northern Lakes Community Mental Health Authority. NLCMHA COVID-19 Response [Internet]. 2020 Mar 15. Available from: https://www.northernlakescmh.org/news-room/nlcmha-covid-19response/. Accessed 22 Jul 2020.

100. Hope Network. COVID-19 updates [Internet]. 2020. Available from: https://hopenetwork.org/about-corporate/covid-19updates/. Accessed 27 Jul 2020.

101. Cherry Health. COVID-19 information [Internet]. 2020. Available from: https://www.cherryhealth.org/resources/covid-19information/. Accessed 27 Jul 2020.
102. Kovanis G. 25 teen girls, 7 staff at Michigan treatment facility infected with coronavirus. Detroit Free Press [Internet]. 2020 May 13. Available from: https://www.freep.com/story/news/ local $/ \mathrm{michigan} /$ detroit $/ 2020 / 05 / 13 / \mathrm{michigan}$-treatmentwolverine-human-services-vassar-coronavirus/3115684001/. Accessed 22 Jul 2020.

103. Rhyan C, Turner A, Ehrlich E, Stanick C. Access to behavioral health care in Michigan: final report [Internet]. 2019. Available from https://altarum.org/sites/default/files/uploaded-publicationfiles/Altarum_Behavioral-Health-Access_Final-Report.pdf. Accessed 8 May 2020.

104. Bojdani E, Rajagopalan A, Chen A, Gearin P, Olcott W, Shankar V, et al. COVID-19 pandemic: impact on psychiatric care in the United States. Psychiatry Res. 2020 Jul 1;289:113069.

105. Haerimana B, Forchuk C, O'Reagon T. The use of technology for mental healthcare delivery among older adults with depressive symptoms: a systematic literature review. Int J Ment Health Nurs. 2019 Jun;28(3):657-70.

106. Juvare, LLC. EMResrouce [Internet]. 2019. Available from https://www.juvare.com/emresource/. Accessed 9 May 2020.

107. OpenBeds. OpenBeds: The Platform [Internet]. 2020. Available from https://openbeds.net/the-platform/. Accessed 9 May 2020.

108. Dexter-Mazza ET, Freeman KA. Graduate training and the treatment of suicidal clients: the students' perspective. Suicide Life Threat Behav. 2002;33(2):211-8. https://doi.org/10.1521/suli.33. 2.211.22769.

109. Schmitz WM, et al. Preventing suicide through improved training in suicide risk assessment and care: an American Association of Suicidology task force report addressing serious gaps in U.S. mental health training. Suicide Life Threat Behav. 2012;42(3):292304. https://doi.org/10.1111/j.1943-278X.2012.00090.x.

110. Posner K, Brown GK, Stanley B, Brent DA, Yershova KV, Oquendo MA, et al. The Columbia-Suicide Severity Rating Scale: initial validity and internal consistency findings from three multisite studies with adolescents and adults. Am J Psychiatry. 2011;168(12):1266-77.

111. CAMS-care. The evidence base for CAMS [Internet]. 2020. Available from https://cams-care.com/about-cams/the-evidencebase-for-cams/. Accessed 8 May 2020.

112. Stanley B, Brown G, Brent DA, Wells K, Poling K, Curry J, et al. Cognitive-behavioral therapy for suicide prevention (CBT-SP): treatment model, feasibility, and acceptability. J Am Acad Child Psy. 2009;48(10):1005-13. https://doi.org/10.1097/CHI. 0b013e3181b5dbfe.

113. Linehan MM, Comtois KA, Murray AM, Brown MZ, Gallop RJ, Heard HL, et al. Two-year randomized controlled trial and followup of dialectical behavior therapy vs therapy by experts for suicidal behaviors and borderline personality disorder. Arch Gen Psychiatry. 2006;63(7):757-66.

114. Covington DW, Hogan MF. Zero suicide: the dogged pursuit of perfection in health care. Psychiatr Times. 2019;36(1):16-7.

115. Aldrich RS, Wilde J, Miller E. The effectiveness of QPR suicide prevention training. Health Educ J. 2018;77(8):964-77. https:// doi.org/10.1177/0017896918786009.

116. Gould MS, Cross W, Pisani AR, Munfakh JL, Kleinman M. Impact of applied suicide intervention skills training on the National Suicide Prevention Lifeline. Suicide Life Threat Behav. 2013;43(6):676-91. https://doi.org/10.1111/sltb.12049.

117. Education Development Center, Inc. About AMSR [Internet]. 2020. Available from http://zerosuicideinstitute.com/amsr/aboutamsr. Accessed 9 May 2020.

Publisher's Note Springer Nature remains neutral with regard to jurisdictional claims in published maps and institutional affiliations. 